\title{
ARTICLES
}

\section{An integrated map of chromosome 18 CAG trinucleotide repeat loci}

\author{
A ndy J G rierson ${ }^{1,5}$, Marjon van Groenigen ${ }^{1}$, Nancy PB G root $^{2}$, Kerstin L indblad $^{3}$, Jan \\ M N Hoovers ${ }^{2}$, Martin Schalling $^{3}$, Jackie de Belleroche ${ }^{4}$ and Frank Baas ${ }^{1}$ \\ ${ }^{1}$ D epartment of N eurology, U niversity of A msterdam, A cademic M edical Center, A msterdam \\ ${ }^{2} \mathrm{D}$ epartment of H uman G enetics, U niversity of A msterdam, A cademic M edical Center, A msterdam, The N etherlands \\ ${ }^{3} \mathrm{~N}$ eurogenetics U nit, Center for M olecular M edicine, K arolinska H ospital, Stockholm, Sweden \\ ${ }^{4} \mathrm{M}$ olecular N eurobiology Research G roup, D epartment of B iochemistry, Charing Cross and Westminster M edical \\ School, L ondon, UK \\ ${ }^{5}$ D epartment of N euroscience, Institute of Psychiatry, D e Crespigny Park, D enmark Hill, L ondon SE 5 8A F, UK \\ (present address)
}

\begin{abstract}
Expansions of trinucleotide CAG repeats have been demonstrated in at least eight neurodegenerative disorders, and suggested to occur in several others, including bipolar disorder and schizophrenia. Chromosome 18 loci have been implicated in bipolar disorder pedigrees by linkage analysis. To address this putative link between chromosome 18 CAG trinucleotide repeats and neuropsychiatric illness, we have screened a chromosome 18 cosmid library (LL 18N C O 2" A D ") and identified 14 novel candidate loci. Characterisation of these loci involved repeat flank sequencing, estimation of polymorphism frequency and mapping using FISH as well as radiation hybrid panels. These mapped trinucleotide loci will be useful in the investigation of chromosome 18 in neurodegenerative or psychiatric conditions, and will serve to integrate physical and radiation hybrid maps of chromosome 18.
\end{abstract}

Keywords: chromosome 18; trinucleotide repeats; FISH ; integrated mapping; neuropsychiatric disorders

\section{Introduction}

A growing number of human diseases are caused by expansions of trinucleotide repeats in their genes. The CA G, CTG, A A G and CCG repeats have so far been implicated in this way. CA G repeats represent the most numerous class of expansions, at present known to account for eight distinct diseases: Kennedy's disease, $\mathrm{H}$ untington's disease, dentatorubral pallidoluysian atrophy and spinocerebellar ataxia types 1, 2, 3, 6 and 7

Correspondence: Frank Baas, U niversity of A msterdam, A cademic Medical Center, PO B ox 22700, 1100D E , A msterdam, The Netherlands. Tel: 3120 5665998; Fax: 3120 5664440; E-mail: f.baas@amc.uva.nl

R eceived 5 February 1998; revised 15 M ay 1998; accepted 11 June 1998 (reviewed by Ross ${ }^{1}$ ). Expansion of CAG repeats may also be involved in other spinocerebellar ataxias, including spinocerebellar ataxia type $5 .^{2}$ These diseases are each characterised by specific neuronal cell death, but share genetic and phenotypic similarities, including progressive neurodegeneration, genetic anticipation, and the translation of the expanded trinucleotide into a polyglutamine stretch in the encoded protein.

A number of other diseases have been suggested to be caused by expansion of as yet unidentified trinucleotide loci, including spinocerebellar ataxias and neuropsychiatric disorders. Evidence for the involvement of expanded CAG/CTG repeats in psychiatric disease came from the repeat expansion detection (RED) technique, ${ }^{3}$ which demonstrated an increased frequency 
of longer CA G/CTG trinucleotides in bipolar disorder and schizophrenia patient DNA compared with control populations. ${ }^{4-6}$ Consistent with this, previous studies suggested this anticipation in psychotic illness. ${ }^{7-10}$

Linkage analysis in the field of psychiatric genetics has a chequered history, ${ }_{1}^{11}$ accounted for by factors such as divergent phenotypes and the existence of multiple disease genes. Recently a number of reports have suggested linkage of bipolar disorder to markers on chromosome $18{ }^{12-14}$ It could be hypothesised that an expanded CA G trinucleotide from this chromosome is involved in the pathogenesis of the disease. Previously Schalling et $\mathrm{al}^{3}$ demonstrated an expanded CA G locus (RED1) on chromosome 18 in CEPH pedigree 1334. A nother expanded chromosome 18 allele recently cloned by B reschel, ${ }^{15}$ was first identified using fluorescence in situ hybridisation (FISH) on metaphases obtained from a schizophrenic individual ${ }^{16}$ This repeat was subsequently excluded from expansion in CEPH pedigree 1334, suggesting the presence of at least two non-allelic CA G repeats which can show expansions on chromosome 18.

There are essentially two distinct strategies available to identify an expanded CA $G$ repeat locus. R andom genome, CDNA or chromosome-wide searches based on screening cosmid or CDNA libraries have been described. ${ }^{17-19}$ In addition novel cloning approaches which are locus specific have been used, including use of the antibody 1C2 which recognises expanded polyglutamine tracts in proteins, ${ }^{20-22}$ as well as the Direct principle ${ }^{23}$ which utilises selective hybridisation or the RAPID screening procedure which uses stringent selection procedures prior to cloning steps. ${ }^{24}$

We set out to identify CA G repeats on chromosome 18, so as to facilitate a systematic screen for possible expansions in bipolar disorder, as has been previously conducted for schizophrenia. ${ }^{25}$ We used a PCR -based cloning strategy to identify CAG repeat loci in a chromosome 18-specific cosmid library derived from a flow-sorted monochromosomal somatic cell hybrid. This method avoids time-consuming subcloning procedures, and since only the repeat flanks are cloned, any cloning bias against longer repeat sequences will be avoided. ${ }^{26,27}$ The new loci were used for a small-scale screen of individuals who showed expanded RED products and were affected with bipolar disorder or other neuropsychiatric conditions.

In addition to identifying novel CA G loci on chromosome 18, we aimed to characterise their polymorphism frequency, and to define precisely their map locations on both genetic and physical maps, which will provide a link between these two types of map. The CAG trinucleotide-containing repeats reported here may help in the mapping of genes for hereditary psychiatric or degenerative disorders, including bipolar disorder and schizophrenia, and will contribute to the development of human STS-based maps.

\section{Materials and Methods}

\section{Hybridisation Conditions}

The chromosome cosmid library LL18NCO2"AD" was replicated in high-density arrays on to $\mathrm{H}$ ybond $\mathrm{N}$ filters using a B iomek 1000 robot (B eckman Instruments Inc., Fullerton, CA, USA ). The filters were hybridised to a ${ }^{32} \mathrm{P}$ labelled $(C A G)_{10}$ oligonucleotide as previously described. ${ }^{3}$ Filters were stringency washed with either $1 \times \mathrm{SSC}$ for normal stringency, or $0.1 \times \mathrm{SSC}$ for high stringency, both at $65^{\circ} \mathrm{C}$ for $15 \mathrm{~min}$. To determine coverage of the library, the forward PCR primer of the G CT5D 07 ST S was ${ }^{32} \mathrm{P}$ labelled as above, and hybridised to the filters.

\section{Vectorette PCR}

Positive clones were isolated and cosmid DNA was prepared using Qiagen columns according to the manufacturer's instructions (Q iagen, G mBH, Hilden, Germany). Cosmid DNA $(0.5 \mu \mathrm{g})$ was digested with one or more restriction enzymes; A lul, $\mathrm{H}$ aellI, EcoRV, R sal. Vectorette PCR was performed essentially as previously described, ${ }^{28}$ except that repeat complementary primers (CA G $)_{6}$ or $(C T G)_{6}$ were used at an annealing temperature of $63^{\circ} \mathrm{C}$ for amplification of repeat-flanking DNA. The repeat flanks were cloned into the pGEM 5 vector (Promega Corp., Madison, WI, USA) by virtue of $5^{\prime}$ terminal $\mathrm{Notl}$ and $\mathrm{N}$ col restriction sites on the PCR primers. Plasmid DNA was prepared using the Wizard Plus kit (Promega Corp., M adison, WI, U SA ), and sequenced using the FS + dye terminator kit (A pplied Biosystems Inc., Perkin E Imer Corporation, Norwalk, Conn., USA ).

\section{Development of CAG Repeat Containing STSs}

Primers were chosen from each of the two amplified flanks of a single cosmid using the GCG Wisconsin package (G enetics Computer G roup, M adison, WI, U SA ). In the event that only a single flank was amplified from a cosmid clone, a single sequencing primer was designed, and direct sequencing of $1 \mu \mathrm{g}$ of PE G-precipitated cosmid DNA was performed. PCR amplification was carried out on $25 \mathrm{ng}$ of genomic DNA in a total volume of $10 \mu$ l consisting of $20 \mathrm{mM}$ dNTPs, $10 \mathrm{ng}$ of each primer, $0.01 \%$ NP $40,0.05 \%$ gelatin, $50 \mathrm{mM} \mathrm{KCl}, 10 \mathrm{~mm}$ Tris ( $\mathrm{pH}$ 8.3-9.9), 1.5-3.5 $\mathrm{mm} \mathrm{M} \mathrm{gCl}_{2}$ and 2 units Taq polymerase for the following cycling times: $94^{\circ} \mathrm{C}$ for 3 min followed by 30 cycles of $94^{\circ} \mathrm{C}$ for $30 \mathrm{~s}, 53-58^{\circ} \mathrm{C}$ (see Table 1) for $30 \mathrm{~s}$, and $72^{\circ} \mathrm{C}$ for $1 \mathrm{~min}$ followed by $72^{\circ} \mathrm{C}$ for $5 \mathrm{~min}$. $\mathrm{M} \mathrm{gCl}_{2}$ concentration (1.5-3.5 mm) and Tris pH (8.3-9.9) were determined empirically for each primer pair. Polymorphism frequency was determined by amplification using the above conditions in the presence of $1 \mathrm{ng}{ }^{33} \mathrm{P}$ dATP end-labelled primer. Products were separated on $6 \%$ denaturing polyacrylamide gels. In some instances unlabelled PCR products were visualised by hybridisation of electro-blotted denaturing 
Table 1 CA G-repeat loci identified in this investigation

\begin{tabular}{|c|c|c|c|c|c|c|c|}
\hline STS & Cosmid ID 1 & PCR primers & Repeat structure & $\mathrm{Tm}^{\circ} \mathrm{C}$ & $\begin{array}{l}\text { Size } \\
\text { (bp) }\end{array}$ & $\begin{array}{l}\text { No. of } \\
\text { alleles }\end{array}$ & $\begin{array}{l}\text { Heterozygote } \\
\text { frequency }\end{array}$ \\
\hline LL 18CAG 10 & $\begin{array}{l}\text { AD } 11 \mathrm{H} 12 \\
\text { AD } 23 E 8 \\
\text { AD } 112 A 6 \\
\text { AD } 63 G 8\end{array}$ & $\begin{array}{l}\text { GGCAAAACACCCATCTTCTCTT } \\
\text { AGCTGCTATGTATTCCAGGCAT }\end{array}$ & $(\mathrm{CAG})_{8}$ & 55 & 149 & 2 & $25 \%$ \\
\hline LL 18CAG 12 & $\begin{array}{l}\text { AD } 12 F 4 \\
\text { AD 31B } 4 \\
\text { AD } 86 A 7\end{array}$ & $\begin{array}{l}\text { GCATTCTTTATTACCCGGCAC } \\
\text { AAAACAAGGACACGCAGAGG }\end{array}$ & $(\mathrm{CAG})_{7} \mathrm{CAA}$ & 55 & 211 & 2 & $67 \%$ \\
\hline LL 18CAG 17 & $\begin{array}{l}\text { AD 16G } 4 \\
\text { AD } 82 \mathrm{H} 2 \\
\text { AD } 57 G 8\end{array}$ & $\begin{array}{l}\text { GCATTTGTTCTCTGGCTCCTTG } \\
\text { GGCA CCCACTAGCACCCT }\end{array}$ & $(\mathrm{CAG})_{4} \mathrm{TAG}(\mathrm{CAG})_{5} \mathrm{CAT}$ & 55 & 225 & 2 & $15 \%$ \\
\hline LL 18CAG 19 & AD $18 \mathrm{H} 6$ & $\begin{array}{l}\text { GCTAATAGGATTAGGATGCTGCTGA } \\
\text { GCACCCTGAAGGTTTCCGT }\end{array}$ & $(\mathrm{CAG})_{6}$ & 56 & 125 & 1 & - \\
\hline LL 18CA G 20 & $\begin{array}{l}\text { AD } 19 C 2 \\
\text { AD } 75 B 9\end{array}$ & $\begin{array}{l}\text { CTTCGCCCCACAAATCCT } \\
\text { CGCCGACATGCCTCAC }\end{array}$ & CAGCATCAC $(C A G)_{6}$ & 55 & 214 & 1 & - \\
\hline LL 18CA G 25 & $\begin{array}{l}\text { AD } 29 \mathrm{H} 4 \\
\text { AD } 31 G 7\end{array}$ & $\begin{array}{l}\text { TGTGAATGGGGAAGGAAGAAG } \\
\text { GGACTGCCAAGAGAATGGAA }\end{array}$ & $(\mathrm{CAG})_{8} \mathrm{CAACAC}$ & 58 & 203 & 3 & $65 \%$ \\
\hline LL 18CAG 30 & $\begin{array}{l}\text { A D 31A } 12 \\
\text { A D 63D } 8 \\
\text { A D 66G } 3 \\
\text { A D 823G3 } \\
\text { A D 89A } 7\end{array}$ & $\begin{array}{l}\text { TTTGGGGAGCACTGAGGG } \\
\text { TTTCCACAGAGAAAGGAAGGG }\end{array}$ & $(\mathrm{CAG})_{8} \mathrm{CAT}$ & 55 & 135 & 4 & $60 \%$ \\
\hline LL 18CAG 31 & $\begin{array}{l}\text { AD } 41 F 12 \\
\text { AD } 129 G 2 \\
\text { AD } 63 D 8\end{array}$ & $\begin{array}{l}\text { ACCAATTTCAGGCCCAA } \\
\text { CAAAGGGTTTCCTGCTTTGA }\end{array}$ & $\begin{array}{l}(\mathrm{CAG})_{2} \mathrm{CAA}(\mathrm{CAG})_{8} \mathrm{CAA} \\
(\mathrm{CAG})_{2} \mathrm{CAA}(\mathrm{CAG})_{7}\end{array}$ & 55 & 196 & 3 & $26 \%$ \\
\hline LL 18CAG 39 & $\begin{array}{l}\text { A D } 65 A 12 \\
\text { A D } 116 \text { A } 5\end{array}$ & $\begin{array}{l}\text { CCTTTTCATTCATGCCAAACT } \\
\text { GGCTTCTGGCTCTGTGTTTCT }\end{array}$ & $(\mathrm{CAG})_{7}$ & 55 & 220 & 1 & - \\
\hline LL 18CA G 48 & A D80E 3 & $\begin{array}{l}\text { GCCACTTGCCCTTCTCCT } \\
\text { GTTCССTTCСTTCATTTTCGTT }\end{array}$ & $(\mathrm{CAG})_{7}$ & 53 & 320 & 1 & - \\
\hline LL 18CAG50 & $\begin{array}{l}\text { AD 38D } 8 \\
\text { AD 81H } 6\end{array}$ & $\begin{array}{l}\text { ССTTTTCTGAAGGCCCCTG } \\
\text { ССTTACСTGGAGGTGAAATGG }\end{array}$ & $(C A G)_{5}$ & 58 & 155 & 1 & - \\
\hline LL 18CA G 61 & $\begin{array}{l}\text { A D 102H } 10 \\
\text { AD 109D } 9\end{array}$ & $\begin{array}{l}\text { ATCTTATTTTCTCCAATTCCCCAG } \\
\text { TCCCTATGATTTCTTTTTGATTGC }\end{array}$ & $(C A G)_{6}$ & 52 & 121 & 1 & - \\
\hline LL 18CA G 73 & AD 132B2 & $\begin{array}{l}\text { CGGCCCCTTCAGGCAG } \\
\text { GAGAACTAAAACCCAGCAGCTAAGA }\end{array}$ & $(\mathrm{CAG})_{6}$ & 55 & 175 & 1 & - \\
\hline LL 18CAG 218 & AD95F3 & $\begin{array}{l}\text { CCCCGCAACAAATCTTTGA } \\
\text { GGGAGATGGGGATAATGGTAATAG }\end{array}$ & TAG $(\mathrm{CAG})_{5} \mathrm{CAT}$ & 54 & 172 & 1 & - \\
\hline
\end{tabular}

"Cosmids were derived from the library LL 18NCO2"A D" (L awrence Livermore National Laboratory)

Multiple I Ds represent independent cosmids containing the same repeat flank sequences. 
polyacrylamide gels with a $(C A G)_{10}{ }^{32} \mathrm{P}$-labelled probe as described above. DNA from 30 unrelated individuals was analysed to determine the polymorphism frequency of the CA G repeat.

\section{Radiation Hybrid Mapping}

The Stanford G 3 (R esearch G enetics Inc., H untsville, A L, USA ) and G enebridge $4^{29}$ radiation hybrid panels were used to place the CAG-containing STSs on the framework radiation hybrid maps. The Stanford $\mathrm{H}$ uman $\mathrm{G}$ enome Center and Whitehead Institute Radiation $\mathrm{H}$ ybrid WWW servers were used for this analysis.

\section{Physical Mapping}

STSs were physically mapped and localised to chromosomal sub-bands by FISH, using the appropriate cosmid DNA. L ocalisation was performed by measuring the relative position of the probe on the chromosome. M ap positions were expressed as the fractional length of the whole chromosome relative to the tip of the $p$ arm (FL pter). ${ }^{30}$ For each cosmid, FLpter values were calculated for 10-15 prometaphase chromosomes and a 95\% confidence interval was calculated. When compared with ideograms in a similar state of contraction, this method gives a very accurate chromosomal assignment. $^{31}$

\section{Screening for Expansions}

A t least three unrelated bipolar affective disorder patients and between nine and 15 individuals with other neuropsychiatric disorders who all showed expanded RED products were screened by PCR using the primers and conditions shown in Table 1 . The products were separated on denaturing $6 \%$ polyacrylamide gels, transferred to nylon membranes and hybridised to a (CAG) probe as described above. M embranes were overexposed to permit the detection of poorly amplified expanded alleles.

Database Analysis of STSs

B last similarity searches were performed at the NCBI using the BlastN server and NR, STS and EST databases.

\section{Results}

\section{Library Screening and STS Development}

The strategy for the identification and analysis of CA G repeat loci is outlined in Figure 1 . To determine the coverage of the LL18NCO2AD cosmid library we hybridised the filters to the forward primer of the GCT5D 07 STS, a CAG trinucleotide repeat locus, which has been mapped to chromosome 18. This identified 7 cosmids containing the STS, predicting a seven-fold coverage of the chromosome in the cosmid library. The filters were then screened with a $(C A G)_{10}$ oligonucleotide probe, washed to normal stringency $(1 \times$ SSC $)$ and 200 positive clones were identified. of these, 73 cosmids were randomly chosen for further analysis. A second high-stringency screen using $0.1 \times$ SSC yielded 66 positive signals, and the 20 strongest clones were chosen. Of these 20 clones 5 had already been identified in the normal stringency screen, and 11 turned out to be duplicates of clones already selected in the normal stringency screen. I nitially triple digests with E CoRV, $\mathrm{H}$ aellI and R sal were performed prior to bubble-anchor ligation. Subsequently multiple single digests were used, to enable a suitably sized flank to be selected for cloning. In total, from the 93 cosmids, data were generated from 66 independent clones. Multiple clones representing 14 novel CA G repeat loci were identified using this approach. We also identified multiple cosmids representing four previously identified chromosome 18 repeat loci (G CT 3E 06, G CT 3G 01, GCT5D 07, GCT6G 01), but we did not isolate clones corresponding to four other CAG loci which had previously been mapped to chromosome 18 (GCT3A 09, GCT7G01， GCT13D 05, CTG 18.1). ${ }^{26,30}$ H owever we subsequently reassigned the GCT3A 09 locus to chromosome 15 (see below). Fourteen additional clones were isolated which corresponded to hamster DNA sequences (data not shown). This was expected as the library contains $10 \%$ hamster clones. Seven uninformative clones gave no flank-PCR products with the (CA G /CTG $)_{10}$ primers, suggesting a falsepositive hybridisation result. Two repeat flanks were derived from the inappropriate amplification of $E$. coli sequences. These were present in the PCR reaction as a result of contamination of the cosmid preparation with genomic DNA. These misamplifications were readily identified by database analysis. If restriction sites had been too close (less than $20 \mathrm{bp}$ ) to the repeat we may have had difficulty in detecting a 40-60 bp PCR product. This problem was usually overcome by choosing another restriction enzyme prior to bubble-anchor ligation. A s expected, multiple clones were identified for several repeats, and this data is summarised in Table 1 along with PCR primers, conditions for PCR, repeat structure and polymorphism frequencies. B riefly, of 14 novel clones, 6 are polymorphic based on the amplification of 30 independent DNA samples (43\%).

\section{Screening for Expansions in a Set of Individuals with Neuropsychiatric Disorders and Long RED Products}

To investigate if any of the novel CAG repeat loci described here are pathologically expanded, a smallscale screen was undertaken. A set of individuals with bipolar affective disorder or other neuropsychiatric disorders where unidentified expansions had previously been detected using RED were used for this screen. A 


$$
\text { screened with }(\mathrm{CAG})_{10} \text { probe }
$$

Normal stringency screen

High stringency screen
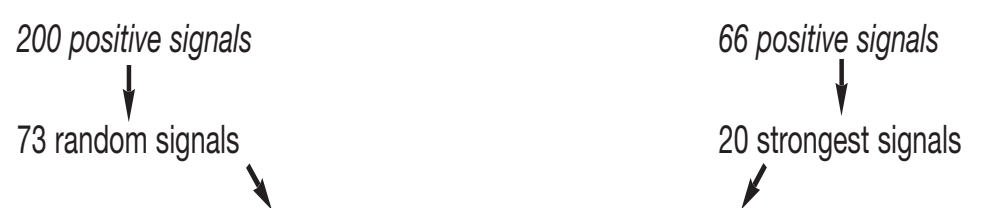

Blunt end digest and ligate vectorette linkers

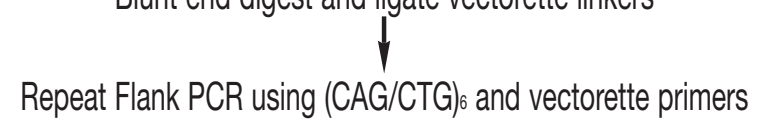

Repeat Flank PCR using $(\mathrm{CAG} / \mathrm{CTG})_{6}$ and vectorette primers

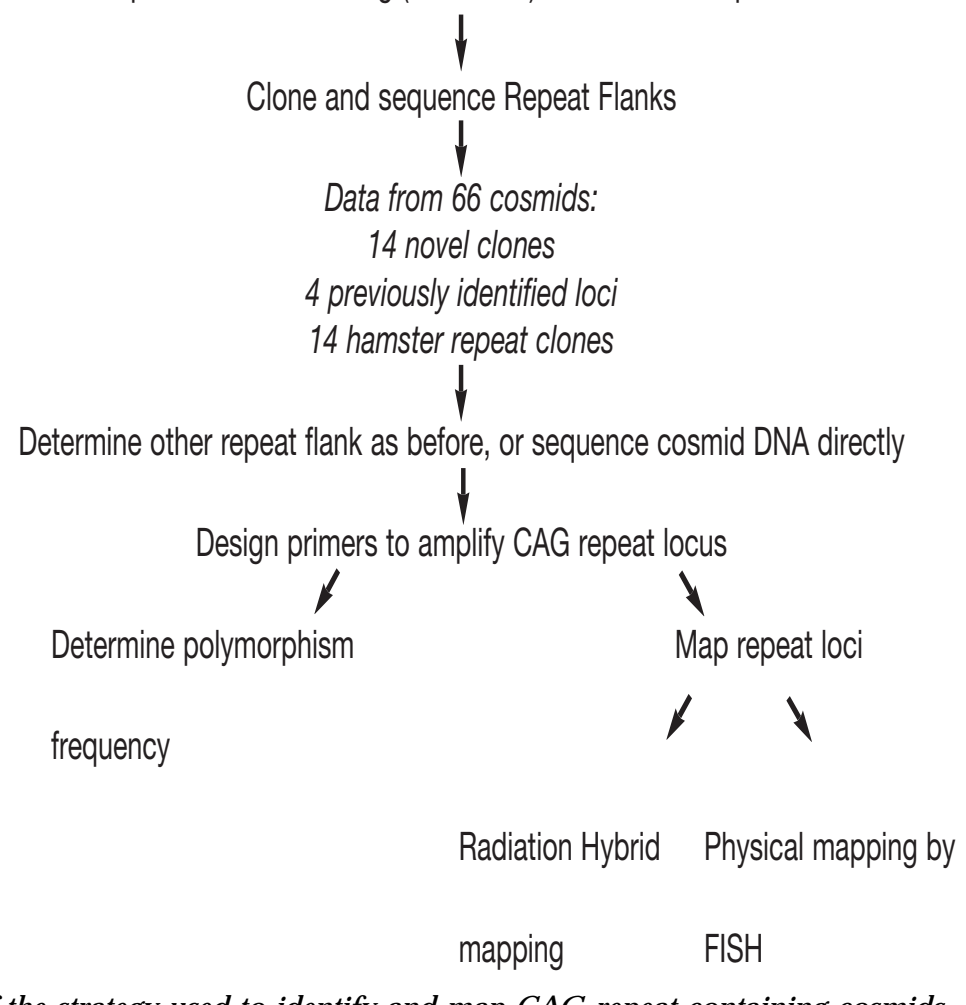

Figure 1 Schematic outline of the strategy used to identify and map CAG repeat containing cosmids.

PCR strategy optimised for detection of poorly amplified expanded alleles was used. A II 14 loci identified in this study were screened in 15 unrelated individuals with either bipolar affective disorder or other neuropsychiatric conditions. The bipolar cases were familial, but not specifically linked to chromosome 18. No expansions at the novel CA G repeat loci were detected in this small set of neuropsychiatric disorder individuals with this screen.

\section{Radiation Hybrid and Physical Mapping of the STSs}

A ll clones were mapped on the Stanford $G 3$ or G enebridge 4 radiation hybrid panels. In order to link the radiation hybrid and physical maps, we also performed FISH with whole cosmids. The results of mapping the STSs are presented in Table 2. The results of both approaches are in good accord, and thus these STSs serve as reference markers linking the two maps. 
Table 2 D atabase homology and map location of chromosome 18 CA G repeat loci

\begin{tabular}{|c|c|c|c|c|c|}
\hline STS & $\begin{array}{l}\text { D atabase } \\
\text { homology }\end{array}$ & $\begin{array}{l}\text { Physical } \\
\text { position } \\
\text { (FL pter) }\end{array}$ & $\begin{array}{l}\text { Sub-band } \\
\text { localisation }\end{array}$ & $\begin{array}{l}\text { L inked } \\
\text { marker on } \\
\text { radiation } \\
\text { hybrid map } 1\end{array}$ & $\begin{array}{l}\text { D istance } \\
\text { from linked } \\
\text { marker } \\
\text { (centiR ays) }\end{array}$ \\
\hline L L 18CA G 10 & $\begin{array}{l}\text { To6032 } \\
\text { Foetal B rain E ST }\end{array}$ & pter & $18 p 11.32$ & D 18S1132 & 6.43 \\
\hline L L 18CA G 12 & $\begin{array}{l}\text { U 55976, H 09960, } \\
\text { R 25492, R 59809, } \\
\text { H 15991, R 19422, } \\
\text { R } 42000 \text { E STs }\end{array}$ & $0.18-0.23$ & 18p11.1-p11.21 & $\begin{array}{l}\text { D } 18 S 1228 \\
\text { D } 18 S 852\end{array}$ & $\begin{array}{l}11.69 \\
14.80\end{array}$ \\
\hline L L 18CA G 17 & - & $0.15-0.18$ & 18p11.21 & D 18S1226 & 63.70 \\
\hline L L 18CA G 19 & - & $0.57-0.72$ & $18 q 12.3-q 21.2$ & D 18S1311 & 33.52 \\
\hline L L 18CA G 20 & $\begin{array}{l}\text { Z78337 } \\
\text { Foetal Brain E ST }\end{array}$ & $0.65-0.74$ & $18 q 21.2-q 21.31$ & D 18S1311 & 31.40 \\
\hline L L 18CA G 25 & - & $0.55-0.66$ & $18 q 12.3-q 21.2$ & D 18S1212 & 14.84 \\
\hline L L 18CA G 30 & - & $0.91-0.95$ & $18 q 22.3$ & D 18S823 & 17.35 \\
\hline L L 18CA G 31 & - & failed & - & D $18 S 1282$ & 4.11 \\
\hline L L 18CA G 39 & - & $0.16-0.19$ & $18 p 11.21$ & WI-5607 & $6.83 \dagger$ \\
\hline L L 18CA G 48 & - & $0.35-0.52$ & $18 q 11.2-q 12.1$ & D $18 S 869$ & $15.55 \dagger$ \\
\hline L L 18CA G 50 & - & $0.9-1.0$ & $18 q 22.3-q 23$ & D 18S1161 & 41.36 \\
\hline \multirow[t]{2}{*}{ L L 18CA G 61} & L 34155 & failed & $18 q 11.2^{*}$ & D $18 S 869$ & 27.10 \\
\hline & LAMA 3 & & & D 18S1067 & 41.10 \\
\hline L L 18CA G 73 & - & pter & 18p11.32 & D 18S1231 & 3.1 \\
\hline L L 18CA G 218 & - & failed & - & D $18 S 60$ & 25.97 \\
\hline G CT 3E 06 & - & - & - & D 18S1161 & 21.20 \\
\hline G CT3G 01 & - & - & - & D 18S828 & $0 \dagger \dagger$ \\
\hline G CT6F 12 & & - & - & D 18S73 & $0 \dagger \dagger$ \\
\hline G CT6G 01 & - & - & - & D 18S58 & 0†† \\
\hline G CT 7G 01 & - & - & - & D 18S542 & 24.09 \\
\hline G CT5D 07 & U 55976 & - & - & D 18S71 & 31.58 \\
\hline GCT13D 05 & - & - & - & D $18 S 869$ & 35.89 \\
\hline GCT3A 09 & - & - & - & D $15 S 148$ & 33.45 \\
\hline
\end{tabular}

$1 \mathrm{M}$ arkers were typed on the StanfordG $3 \mathrm{R}$ adiation $\mathrm{H}$ ybrid panel unless indicated otherwise.

*FISH failed, sequence identity to LA M A 3 which is al ready mapped to 18q11.2.

†These markers were typed on the $\mathrm{G}$ enebridge4 hybrid panel.

t†These markers are present on the $\mathrm{G}$ enebridge4 hybrid map.

Three of the novel loci, L L 18CA G 31, L L 18CA G 61 and LL 18CA G 218, failed to give interpretable FISH data. Clone LL 18CAG 61 showed sequence identity to the L A M A 3 gene, which allows us to map it to 18p11.2. We also used radiation hybrid panels to map the previously identified markers GCT3E 06, GCT3G 01, GCT5D 07, GCT6G 01, G CT 3A 09, G CT 7G 01 and G CT 13D 05. It is noteworthy that we found GCT3A 09 mapped to chromosome 15 using the Genebridge 4 radiation hybrid panel (Table 2). This STS had previously been mapped to chromosome 18 using the NIG M S panel. ${ }^{18}$

\section{Database Homology Analysis}

The rapidly expanded database service at the NCBI enables the rapid cross-referencing of new and existing sequence data from diverse sequencing projects. The E ST and Non-R edundant (NR) databases enable us to predict which of the CAG-repeat sequences are expressed. Expression of the $C A G$ repeat is particularly relevant to the involvement of these repeats in human genetic diseases, and this data is presented in Table 2. Of the novel genomic clones presented here, four had perfect homologies with expressed $\mathrm{G}$ enbank sequences. In one instance the repeat was within the homologous region, LL 18CA G 20, which was also identified by Neri et al. $^{19}$ In the remaining three cases the flanking sequence rather than the $C A G$ repeat was homologous to an E ST sequence ( $L$ L 18CA G 10, 12 and 61), suggesting that the repeat sequence is located in the proximity of an EST, but is not necessarily exonic.

\section{Discussion}

We have identified 18 chromosome 18 CAG-repeat containing STSs of which 14 are novel. These clones, 
together with the previously reported chromosome 18 loci may be used for screening diseases associated with the expansion of CAG repeats on this chromosome. The vectorette PCR techniques used here ${ }^{28}$ demonstrate the efficacy of 'cloning' CAG repeats without actually cloning the potentially unstable CA G repeat itself. This may be useful to investigators interested in trying to identify novel expanded repeats in human genomic DNA.

O ur extensive analysis of the repeat loci identified here enables comparisons to be drawn with other studies which have identified CA G repeats. Gastier et $\mathrm{al}^{18}$ reported the largest set of CA G -based ST Ss to date, including 8 loci on chromosome 18. We have shown that one of these markers is actually located on chromosome 15, and confirmed the data for four of the others. Taken together with another locus identified by $\mathrm{Bre}$ schel et $\mathrm{al}^{1,}{ }^{15}$ we now know the location of 22 different CA G -repeat loci on this chromosome. $\mathrm{O}$ the basis of hybridisation with a single copy probe, we originally estimated there were 22-27 CA G loci represented in the library based on 200 positives in a library comprising 14000 clones (of which 1400 are likely to be hamster clones) with 7-fold coverage. In fact we isolated 14 hamster CA G repeat loci (data not shown) which is in keeping with these calculations. Since we failed to identify clones representing four other loci in our analysis of 93/200 clones it is possible that portions of the chromosome are not equally or adequately represented in the cosmid library. Of the clones for which we generated human CA G repeat sequence data, we usually identified at least two cosmids representing each repeat locus, with a mean of 1.6 cosmids, and a range of 1 to 5 cosmids per locus. This data is based on the identification of multiple copies within the 93 clones chosen from 200 hybridisation signals, and is not based upon rescreening the library with each novel clone. Therefore, we propose that it is unlikely that we have failed to identify a significant number of CAG loci present in this library, and suggest that any chromosome 18 loci which we failed to identify are likely to be absent from, or under-represented in, this library.

O ur polymorphism analysis demonstrated that $6 / 14$ $(43 \%)$ of the novel repeats were polymorphic. Inclusion of polymorphism data for the other chromosome $18 \mathrm{loci}^{32,33}$ and our own analysis of six of these loci (data not shown), revealed that 5/8 (63\%) loci were polymorphic. Thus in total, of 22 loci on chromosome 18,11 were polymorphic $(50 \%)$. It has been suggested that loci containing greater than nine repeat units are the most likely to be polymorphic, and this likelihood is increased further for perfect repeats containing only CA G motifs, compared with complex repeats which are interspersed with CAA or CAC or AAG trinucleotides. ${ }^{19} \mathrm{H}$ owever, the SCA 6 repeat in the $3^{\prime}$ end of the $\alpha 1_{A}$-voltage dependent calcium channel may contain as few as four CAG repeats on normal chromosomes, ${ }^{34}$ so it seems to be the case that shorter and less polymorphic repeats may be candidates for diseaseassociated expansion. It is interesting to note that our longest CAG clone, LL18CAG31, containing 22 imperfect repeats, also has a low polymorphism frequency, with only three alleles, one of which has an allele frequency of 0.94 . The sequence of the repeat at this locus is $\left.(\mathrm{CA} \mathrm{G})_{2} \mathrm{CA} \mathrm{A}(\mathrm{CA} \mathrm{G})_{8} \mathrm{CA} \mathrm{A}(\mathrm{CA} \mathrm{G})_{2} \mathrm{CA} \mathrm{A} \mathrm{(CA} \mathrm{G}\right)_{7}$.

The identification, cloning, and integrated mapping of 14 novel and eight previously identified CA G repeatcontaining loci on human chromosome 18 will be of use to investigations of neuropsychiatric disorders. For example, bipolar disorder demonstrates anticipation and has been associated with CA G /CTG repeat expansions. It is also possible that a locus on chromosome 18 contributes to this disorder. We therefore analysed a number of unrelated bipolar samples where repeat expansions had previously been identified using the RED technique. These were familial cases, but not specifically families linked to chromosome 18. A Ithough no expansions were found in this preliminary screen, firm conclusions regarding the involvement of any of these new CA G repeat loci would have to await a more comprehensive analysis of chromosome 18 linked families. A small sample of unmapped neuropsychiatric disorders were also tested because of the presence of verified RED expansions. A lthough no expansions were detected, it would be premature to rule out the involvement of these chromosome 18 loci in neuropsychiatric disorders based only on this limited patient sample.

\section{Acknowledgements}

We thank the YAC Screening Service at Leiden for use of their Biomek robot when replicating the cosmid library. We acknowledge the HGMP for providing the Genebridge 4 radiation hybrid panel. $A J G, M G$ and $K L$ were funded by an EU Biomed award. We thank A LMA ten A sbroek, Drs W Scheper, LJ Valentijn, R Versteeg and A Westerveld for critical comments on this manuscript. 


\section{References}

1 Ross CA : Intranuclear neuronal inclusions: A common pathogenic mechanism for glutamine-repeat neurodegenerative diseases? Neuron 1998; 19: 1147-1150.

2 Ranum LP, Schut LJ, L undgren JK, O rr HT, Livingston D M : Spinocerebellar ataxia type 5 in a family descended from the grandparents of President Lincoln maps to chromosome 11. Nat G enet 1994; 8: 280-284.

3 Schalling $M$, Hudson TJ, Buetow KH, Housman DE: $D$ irect detection of novel expanded trinucleotide repeats in the human genome. $\mathrm{N}$ at $\mathrm{G}$ enet 1993; 4: 135-139.

4 O'Donovan MC, Guy C, Craddock N et al: Expanded CA G repeats in schizophrenia and bipolar disorder. $\mathrm{N}$ at Genet 1995; 10: 380-381.

5 M orris A G, G aitonde E, M cK enna PJ, M ollon JD, H unt D M : CA G repeat expansions and schizophrenia: association with disease in female and with early age-at-onset. H um M ol G enet 1996; 4: 1957-1961.

6 O 'D onovan M C, Craddock G N, B owen T et al: Confirmation of association between expanded CA G/CTG repeats and both schizophrenia and bipolar disorder. P sychol M ed 1996; 26: 1145-1153.

7 M clnnis M G, M CM ahon FJ, Chase G A, Simpson SG, R oss CA, DePaulo JR jr: A nticipation in bipolar affective disorder. A m J H um G enet 1993; 53: 385-390.

8 A sherson P, Walsh C, Williams J et al: Imprinting and anticipation. A re they relevant to genetic studies of schizophrenia? B r J P sychiatry 1994; 16: 619-624.

9 Bassett AS, Honer WG: Evidence for anticipation in schizophrenia. A m J H um G enet 1994; 54: 864-870.

10 Nylander PO, Engstrom C, Chotai J, Wahlstrom J, A dolfsson R: Anticipation in Swedish families with bipolar affective disorder. J Med Genet 1994; 31: 686-689.

11 Risch N, B otstein D: A manic depressive history. Nat G enet 1996; 12: 351-353.

12 Berrettini WH, Feraro TN, Goldin LR et al: Chromosome 18 D NA markers and manic-depressive illness: Evidence for a susceptibility gene. P roc N atl A cad Sci U SA 1994; 91: 5918- 5921

13 Stine OC, Xu J, Koskela $\mathrm{R}$ et al: Evidence for linkage of Bipolar D isorder to chromosome 18 with parent-of-origin effect. A m J H um G enet 1995; 57: 1384-1394.

14 Fremier NB, Reus VI, Escamilla MA et al: Genetic mapping using haplotype, association and linkage methods suggests a locus for severe bipolar disorder (BPI) at 18q22-q23. N at G enet 1996; 12: 436-441.

15 Breschel TS, Mclnnis MG, Margolis RL et al: A novel, heritable, expanding CTG repeat in an intron of the SE F21 gene on chromosome 18q21. Hum Mol G enet 1997; 6(11): 1855-1863.

$16 \mathrm{H}$ aaf T, Sirugo G, Kidd KK, Ward DC: Chromosomal localization of long trinucleotide repeats in the human genome by fluorescence in situ hybridization. $\mathrm{N}$ at $\mathrm{G}$ enet 1996; 12: 183-185.

17 Gastier JM, Pulido JC, Sunden S et al: Survey of trinucleotide repeats in the human genome: assessment of their utility as genetic markers. H um M ol Genet 1995; 4: 1829-1836.

18 G astier J M, B rody T, Pulido JC et al: D evelopment of a screening set for new (CAG/CTG) n dynamic mutations. Genomics 1996; 32: 75-85.
19 Neri C, A lbanese V, L ebre A S et al: Survey of CA G/CTG repeats in human $C D N A$ s representing new genes: candidates for inherited disorders. Hum Mol G enet 1996; 5: 1001-1009.

20 Trottier Y, Lutz Y, Stevanin G et al: Polyglutamine expansion as a pathological epitope in Huntington's disease and four dominant cerebellar ataxias. Nature 1995; 378: 403-406.

21 I mbert G, Saudou F, Y vert G et al: Cloning of the gene for spinocerebellar ataxia 2 reveals a locus with high sensitivity to expanded CA G/glutamine repeats. N at G enet 1996; 14: 285-291.

22 Stevanin G, Trottier $Y$, Cancel G et al: Screening for proteins with polyglutamine expansions in autosomal dominant cerebellar ataxias. Hum Mol Genet 1996; 5: 1887-1892.

23 Sanpei K, Takano H, I garashi S et al: Identification of the spinocerebellar ataxia type 2 gene using a direct identification of repeat expansion and cloning technique, DIRE CT. $N$ at $G$ enet 1996; 14: 277-284.

24 Koob M D, B enzow KA, B ird TD, D ay JW, M oseley ML, R anum LPW: Rapid cloning of expanded trinucleotide repeat sequences from genomic D NA . N at G enet 1998; 18: 72-76.

25 Bowen T, Guy C, Speight G et al: Expansion of 50 CA G / CTG repeats excluded in schizophrenia by application of a highly efficient approach using repeat expansion detection and a PCR screening set. A m J H um G enet 1996; 59: 912-917.

26 Gibbs M, Collick A, Kelly R G, Jeffreys A J : A tetranucleotide repeat mouse minisatellite displaying substantial instability during early preimplantation development. Genomics 1993; 17: 121-128.

27 K ang S, Jaworski A, O hshima K, Wells R D : Expansion and deletion of CTG repeats from human disease genes are determined by the direction of replication in $\mathrm{E}$. coli. $\mathrm{N}$ at $\mathrm{G}$ enet 1995; 10: 213-218.

28 M unroe DJ, $H$ aas $M$, W hitton T et al: IRE -Bubble PCR : A rapid method for efficient and representative amplification of human genome DNA sequences from complex sources. G enomics 1994; 19: 506-514.

29 G yapay G, Schmitt K, Fizames $C$ et al: A radiation hybrid map of the human genome. Hum Mol Genet 1996; 5: 339-346.

30 Lichter $\mathrm{P}$, Tang CJ C, Call $\mathrm{K}$ et al: $\mathrm{H}$ igh-resolution mapping of human chromosome 11 by in situ hybridization with cosmid clones. Science 1990; 247: 64-69.

31 Hoovers J M H, M annens $M$, J ohn $R$ et al: $H$ igh-resolution localisation of 69 potential human zinc finger protein genes: A number are clustered. Genomics 1992; 12: 254-263.

32 Giacalone J, Li X, Lehrach H, Francke U : High-density radiation hybrid map of human chromosome 18 and contig of 18p. G enomics 1996; 37: 9-18.

33 Schuler G D, B oguski M S, Stewart E A et al: A gene map of the human genome. Science 1996; 274: 540-546.

34 Zhuchenko $\mathrm{O}$, Bailey J, Bonnen $\mathrm{P}$ et al: A utosomal dominant cerebellar ataxia (SCA 6) associated with small polyglutamine expansions in the $\alpha 1_{\mathrm{A}}$-voltage-dependent calcium channel. N at G enet 1997; 15: 62-69. 